\title{
Metal contamination and coexistence of metal and antibiotic resistance in Vibrio species recovered from aquaculture ponds with and without history of antibiotic usage in Southwest Nigeria
}

\author{
Abimbola Olumide Adekanmbi* $\mathbb{D}$, Ololade Grace Olawuni and Adedolapo Victoria Olaposi
}

\begin{abstract}
Background: The use of metal-containing and antimicrobial compounds is a common practice in aquaculture operations in Nigeria. Only a few studies have focused on the impact of these chemicals on metal and antibiotic resistance development in the bacterial flora of aquaculture. This study therefore sets out to fill this gap.

Results: Five metals, namely copper (Cu), zinc ( $\mathrm{Zn}$ ), lead (Pb), nickel ( $\mathrm{Ni}$ ) and chromium (Cr), were detected at different concentrations in the pond water samples, with most values obtained exceeding the maximum recommended national standard for fisheries and recreation water quality criteria set by the National Environmental Standards and Regulations Enforcement Agency (NESREA) in Nigeria. A total of 121 Vibrio spp. were recovered from the aquaculture pond water with Vibrio cholerae having the highest frequency (37) followed by Vibrio parahaemolyticus (36), Vibrio vulnificus (36) and Vibrio alginolyticus (12). Seventy-five isolates were recovered from ponds with history of antibiotic use, while the ponds with no recognized history of antibiotic use had forty-six isolates. The percentage resistance to antibiotics in the isolates was: ampicillin (88.5\%), amoxicillin-clavulanate (44.3\%), tetracycline (41\%), trimethoprimsulfamethoxazole (22.1\%), chloramphenicol (15.6\%), ciprofloxacin (11.5\%), imipenem (5.7\%), ceftazidime (4.1\%) and gentamicin (0\%). All the isolates tolerated all the metals to $400 \mu \mathrm{g} / \mathrm{mL}$ concentration while only the trio of Pb, $\mathrm{Ni}$ and Cr were tolerated beyond the concentration. Zn and $\mathrm{Cu}$ appeared to be the most toxic metals on Vibrio spp., with no isolate surviving beyond the $400 \mu \mathrm{g} / \mathrm{mL}$ concentration mark, while 57 of the 121 isolates survived $\mathrm{Cr}$ at the highest concentration $(3200 \mu \mathrm{g} / \mathrm{mL})$, making it the most tolerated of the metals.
\end{abstract}

Conclusion: This study reports a high level of metal contamination in the aquaculture ponds studied. The concentration of the metals exceeded the maximum permissible limits in Nigeria. Also, there was coexistence of metal and antibiotic resistance in the bacteria recovered from the aquaculture ponds. There is a need to regulate the use of chemicals, especially antibiotics and some biocidal compounds, to clamp down on the introduction of metals and antibiotics into the aquaculture systems, as these chemicals could facilitate the development of resistance traits in aquaculture bacteria by creating a selective pressure in the aquaculture environment.

Keywords: Antibiotic resistance, Antibiotic usage, Aquaculture ponds, Clarias gariepinus, Heavy metal contamination, Metal resistance, Vibrio spp.

\footnotetext{
*Correspondence: ao.adekanmbi@ui.edu.ng; bimboleen@yahoo.com

Environmental Microbiology and Biotechnology Laboratory, Department

of Microbiology, University of Ibadan, Ibadan, Nigeria
} 


\section{Background}

Nowadays, aquaculture is regarded as one of the major contributors to food security in agriculture worldwide. It ranks as one of the fastest growing sectors in the agricultural industry in some countries of the world, with freshwater aquaculture dominating the total aquaculture production. Aquaculture serves as a source of quality food supply at low cost to Africans, generates income for farming and fishing households and plays a key role in the economy of many nations (Kitessa et al. 2014; Pradeepkiran 2019).

Currently, there has been a great loss in the aquaculture industry as a result of the occurrence of diseases, including vibriosis caused by Vibrio spp. which is one of the most common diseases that affect shelled organisms: molluscs and crustaceans. Vibrio belong to the family Vibrionaceae. They are Gram-negative, comma- or rod-shaped, facultative anaerobes (CDC 2014). They are commonly found in the aquatic habitats where they constitute a part of the natural microflora (Maheshwari et al. 2011). Most Vibrio species are pathogenic to human and have been linked with food-borne diseases such as diarrhea and cholera.

In order to prevent disease outbreak and loss in the aquaculture industry, the use of antibiotics has been employed. However, it has been established that the high rate of antibiotic-resistant bacteria in the aquatic environment is linked to the undue and unrestricted usage of antibiotics in aquaculture farming (Hui-Gao et al. 2018), resulting in the onset of resistance (Narendrakumar et al. 2019). Bacterial resistance to antibiotics is a genetic phenomenon caused by genes within the organisms that encode different biochemical mechanisms and prevent the action of these drugs, and these are known as antibiotic resistance genes (ARG) (Gonzalez-Candelas 2011). Resistance to antibiotics in the aquatic environment is even more serious because some bacteria have the ability to transfer their genes to others. There is a linkage between antibiotic and metal resistance in the environment, as it has been observed in some cases that the presence of heavy metals in the environment could trigger the resistance of microorganisms to antibiotics since both resistance genes are frequently located on the same mobile genetic elements (Hatha et al. 1993; McIntosh et al. 2008; Fang et al. 2019).

Metals occur in the natural environment and also as products of different anthropogenic activities. However, they can also be present as contaminants in fish feed, a scenario that has been reported by several authors. Kundu et al. (2017) reported the presence of elevated concentration of $\mathrm{Cd}, \mathrm{Fe}, \mathrm{Na}$ and $\mathrm{Pb}$ in fish feed obtained in Bangladesh, while the occurrence of $\mathrm{Pb}, \mathrm{Cr}$ and $\mathrm{Cd}$ in fish feed was confirmed by the report of Sabbir et al.
(2018). Bacteria have developed very efficient and different mechanisms for tolerating heavy metal stress through either the presence of genes or other mobile genetic elements.

The use of antibiotics in aquaculture as growth promoters and for therapeutic purposes coupled with the presence of metals and antibiotics in fish feed could facilitate the development of antibiotic and metal resistance in bacteria resident in aquaculture ponds. Therefore, there is a need to investigate aquaculture ponds for the occurrence of metal- and antibiotic-resistant bacteria because of their predisposition to both metals and antibiotics, visà-vis determining the metal concentration of the selected ponds. This study aimed at isolating and characterizing Vibrio spp. from aquaculture ponds water samples and determining their resistance to both metals and selected antibiotics.

\section{Methods}

\section{Description of study site, aquaculture ponds and sample collection}

This study was carried out in Awotan, a suburban area in Ido Local Government Area, Ibadan, Oyo State, Nigeria. A total of twenty-six (26) earthen and concrete aquaculture ponds were sampled from five representative commercial fish farms in the area. The fish farms are located at Alakuta, Trailer park, Kelanko and Flash areas of the Awotan community and the species of fish being reared on all the farms is Clarias gariepinus. The pond type, water sources and location are given in Table 1 . There is a history of antibiotic usage in some of the aquaculture ponds, and the main antibiotics used in their operation are ampicillin, streptomycin, enrofloxacin, tetracycline and chloramphenicol. In some of the aquaculture ponds, no information on antibiotic usage was provided at the time this study was executed and as a result, they were classified as ponds without a recognized or reported history of antibiotic usage. Water samples were collected from the aquaculture ponds in pre-cleaned sterile sample bottles weekly for a period of three months. The water samples were transported to Environmental Microbiology and Biotechnology laboratory, Department of Microbiology, University of Ibadan, Nigeria, in ice packs for processing. Samples were analyzed within three hours of collection.

\section{Metal composition of the aquaculture water samples}

The concentration of selected metals in the water samples was determined using the atomic absorption spectrophotometer (AAS) (UNICAM 929, London Atomic Absorption Spectrophotometer powered by SOLAAR software). Standards of $\mathrm{Cu}, \mathrm{Zn}, \mathrm{Cd}, \mathrm{Pb}$ and $\mathrm{Ni}$, with range of calibration from 0.2 to $1.0 \mathrm{mg} / \mathrm{L}$, were prepared from 
Table 1 Description of the aquaculture ponds used in this study

\begin{tabular}{|c|c|c|c|c|}
\hline Aquaculture ponds & Pond type & Water source & Location & $\begin{array}{l}\text { Antibiotic } \\
\text { usage }\end{array}$ \\
\hline Aq ponds 1-3 & Concrete & Borehole, water well & Alakuta & No \\
\hline Aq ponds 4-7 & Concrete & River, stream & Alakuta & No \\
\hline Aq ponds 8 & Earthen & River & Alakuta & No \\
\hline Aq ponds 9-12 & Earthen & Stream & Trailer park & No \\
\hline Aq ponds 13-19 & Earthen & Stream & Kelanko & Yes \\
\hline Aq ponds 20-26 & Earthen & Stream & Flash & Yes \\
\hline
\end{tabular}

Aq: Aquaculture; Yes: recognized history of antibiotic use; None: no recognized history of antibiotic use

$1000 \mathrm{mg} / \mathrm{L}$ stock solution analytes of the respective metal. The detection limit for each metal was $0.0001 \mathrm{mg} / \mathrm{L}$. The cathode lamp of each metal was used in the analysis of the respective metal concentration in the standards (used as a control) and the sample filtrates (Hseu 2004).

\section{Isolation of Vibrio spp.}

The streak plate method was employed in the isolation of Vibrio spp. from the water samples on CHROMagar Vibrio (CHROMagar, France), a chromogenic medium, for the detection and isolation of Vibrio spp. Colonies presumptive of Vibrio spp. were selected and repeatedly subcultured to obtain pure isolates which were further confirmed using conventional methods. The working cultures were maintained on agar slant under refrigeration condition while the cultures for long-term storage were stored in $15 \%$ glycerol kept at $-80^{\circ} \mathrm{C}$.

\section{Antibiotic susceptibility testing}

The in-vitro susceptibility of the Vibrio isolates to nine selected classes of antibiotics was carried out using the disk diffusion method (CLSI 2018). The antibiotics used were gentamicin $(30 \mu \mathrm{g})$, ciprofloxacin $(5 \mu \mathrm{g})$, chloramphenicol $(30 \mu \mathrm{g})$, tetracycline $(30 \mu \mathrm{g})$, amoxicillin-clavulanate $(30 \mu \mathrm{g})$, ceftazidime $(30 \mu \mathrm{g})$, imipenem $(30 \mu \mathrm{g})$, trimethoprim-sulfamethoxazole $(23.75 / 1.25 \mu \mathrm{g})$ and ampicillin $(30 \mu \mathrm{g})$. The zones of inhibition were measured and interpreted using the CLSI (2018) standard. Sensitive, intermediate and/or resistant phenotypes were reported according to the established breakpoints for Vibrio spp. Isolates showing resistance to three or more classes of antibiotics were classified as multidrug-resistant as described by Magiorakos et al. (2012).

\section{Determination of minimum inhibitory concentration (MIC) of metals on the isolates}

The determination of the MIC of selected metals on the isolates was carried out using the doubling concentration method. Appropriate volume of filter-sterilized solutions of prepared metals was incorporated into sterilized, molten nutrient agar, mixed gently and poured into sterile plates. An 18-24 h old culture of the isolates was streaked on the metal-incorporated medium and incubated at $35 \pm 2{ }^{\circ} \mathrm{C}$. The plates were observed for growth for $48 \mathrm{~h}$. The culture growing on a particular concentration was then transferred to the next higher concentration until no growth was observed. The concentration at which growth stopped was recorded as the MIC. The concentration of each heavy metal was doubled each time from an initial concentration of $6.25 \mu \mathrm{g} / \mathrm{mL}$ to a final concentration of $3200 \mu \mathrm{g} / \mathrm{mL}$ (Yu et al. 2016). The metal salts used in this study were $\mathrm{NiCl}_{2}, \mathrm{CrCl}_{3}, \mathrm{PbCl}_{2}$, $\mathrm{CuSO}_{4}$ and $\mathrm{ZnSO}_{4}$.

\section{Results}

Metal concentration in aquaculture pond water samples

The metal concentration of water samples obtained from ten of the total twenty-six aquaculture ponds sampled in this study is shown in Table 2. With the exception of ponds 1-4 with no detectable amount of Ni, all the other metals assayed for were detected at different concentrations in the aquaculture ponds. The concentration of $\mathrm{Zn}$ was highest in pond $10(2.82 \mathrm{mg} / \mathrm{L})$, with ponds 9 and 10 having the highest $\mathrm{Pb}$ concentration of $0.29 \mathrm{mg} / \mathrm{L}$. Pond 7 had the highest level of $\mathrm{Cr}$ at $2.11 \mathrm{mg} / \mathrm{L}$, with $\mathrm{Cu}$ being highest at pond $8(0.09 \mathrm{mg} / \mathrm{L})$. Nickel was highest at pond $6(0.80 \mathrm{mg} / \mathrm{L})$. The concentration of $\mathrm{Cu}$ in the water samples ranged from 0.01 to $0.09 \mathrm{mg} / \mathrm{L}$.

\section{Frequency and distribution of Vibrio spp. in the aquaculture ponds}

A total of one hundred and twenty-one isolates was obtained from the aquaculture ponds. The frequency of Vibrio species is as follows: Vibrio cholerae (37), Vibrio parahaemolyticus (36), Vibrio vulnificus (36) and Vibrio alginolyticus (12). The distribution of the Vibrio spp. according to the ponds with or without history of antibiotic usage is shown in Table 3. A total of 75 isolates were obtained from the ponds with confirmed history of antibiotic usage and 46 from the ponds without history 


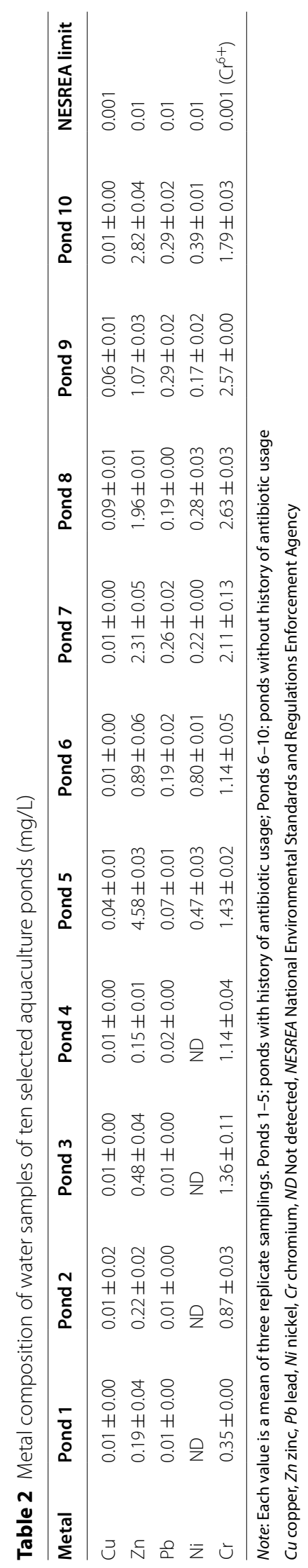


Table 3 Frequency of occurrence of Vibrio species in the aquaculture ponds

\begin{tabular}{lll}
\hline Vibrio spp. & $\begin{array}{l}\text { Ponds with antibiotic } \\
\text { usage }\end{array}$ & $\begin{array}{l}\text { Ponds with } \\
\text { no antibiotic } \\
\text { history }\end{array}$ \\
\hline V. vulnificus & 21 & 15 \\
V. parahaemolyticus & 19 & 18 \\
V. cholerae & 23 & 13 \\
V. alginolyticus & 12 & 0 \\
Total & 75 & 46 \\
\hline
\end{tabular}

of antibiotic usage. No Vibrio alginolyticus was isolated from the pond without history of antibiotic use.

\section{Survival of the Vibrio spp. at increasing concentration of heavy metals}

The survival of the Vibrio spp. isolated from aquaculture ponds on increasing concentration of five selected metals is shown in Fig. 1. There was $100 \%$ survival of organisms at $6.25 \mu \mathrm{g} / \mathrm{mL}$ to $50 \mu \mathrm{g} / \mathrm{mL}$ concentration of the metals. However, there was reduction in the rate of survival as the concentration increased. At $400 \mu \mathrm{g} / \mathrm{mL}$ concentration, 118 of the total 121 isolates were still surviving on $\mathrm{Pb}, 120$ isolates on $\mathrm{Ni}, 117$ isolates on $\mathrm{Cr}, 24$ isolates and 16 isolates surviving, respectively, on $\mathrm{Zn}$ and $\mathrm{Cu}$. $\mathrm{Zn}$ and $\mathrm{Cu}$ are the most toxic metals to the Vibrio spp. with none of the isolates surviving at $800 \mu \mathrm{g} / \mathrm{mL}$ concentration of the two metals, while $\mathrm{Cr}$ was the least toxic of the metals to the isolates, with 57 of the total 121 isolates surviving at the highest concentration used in this study $(3200 \mu \mathrm{g} /$ $\mathrm{mL})$.

\section{Resistance of the Vibrio spp. to tested antibiotics}

The resistance of the Vibrio spp. isolated from this study to the tested antibiotics is shown in Fig. 2. Of the total isolates, $88.5 \%$ were resistant to ampicillin and $44.3 \%$ showed resistance to amoxicillin-clavulanate. There was $41 \%$ resistance to tetracycline and $22.1 \%$ resistance to trimethoprim-sulfamethoxazole, while $15.6 \%$ of the total isolates showed resistance to chloramphenicol. No resistance was observed to gentamicin, and $11.5 \%, 5.7 \%$ and $4.1 \%$ of the total isolates showed resistance to ciprofloxacin, imipenem and ceftazidime, respectively.

The resistance to antibiotics in Vibrio spp. isolated from ponds with history of antibiotic usage and the ponds without a recognized history of the use of antibiotics is shown in Fig. 3. There was no resistance to gentamicin from isolates obtained from both groups, whereas there was $40 \%$ resistance to tetracycline in ponds with usage of antibiotics as against $52.2 \%$ in ponds without the use of antibiotics. There was $61.3 \%, 14.7 \%, 8 \%$ and $21.3 \%$ resistance to ampicillin, imipenem, ciprofloxacin and trimethoprim-sulfamethoxazole, respectively, in the ponds with history of antibiotic usage as against $73.9 \%, 6.5 \%, 21.7 \%$ and $23.9 \%$ resistance to the same sets of antibiotics in ponds without antibiotic history. To ceftazidime, chloramphenicol and amoxicillin-clavulanate, there was 5.3\%, $9.3 \%$ and $46.7 \%$ resistance in ponds with antibiotic

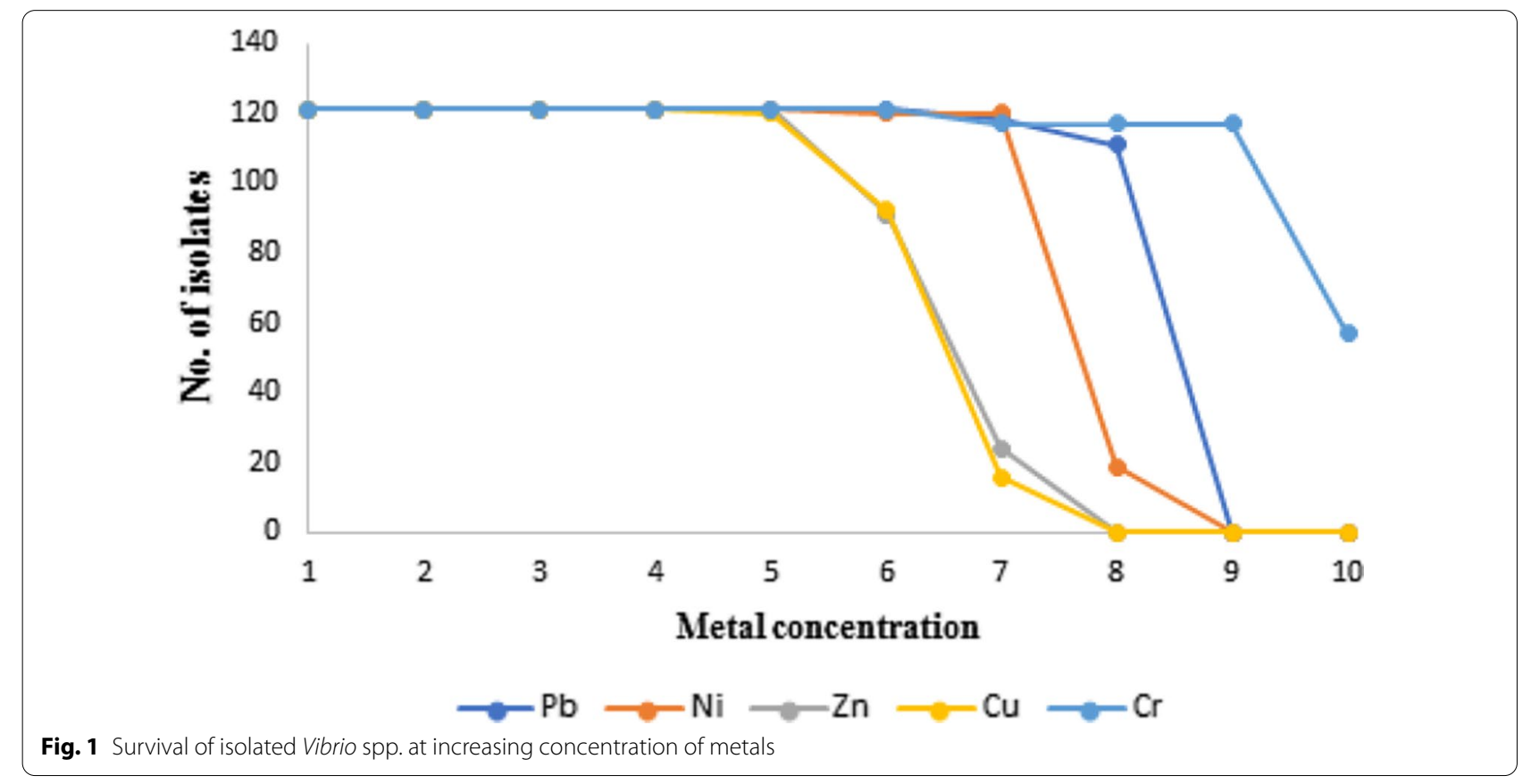




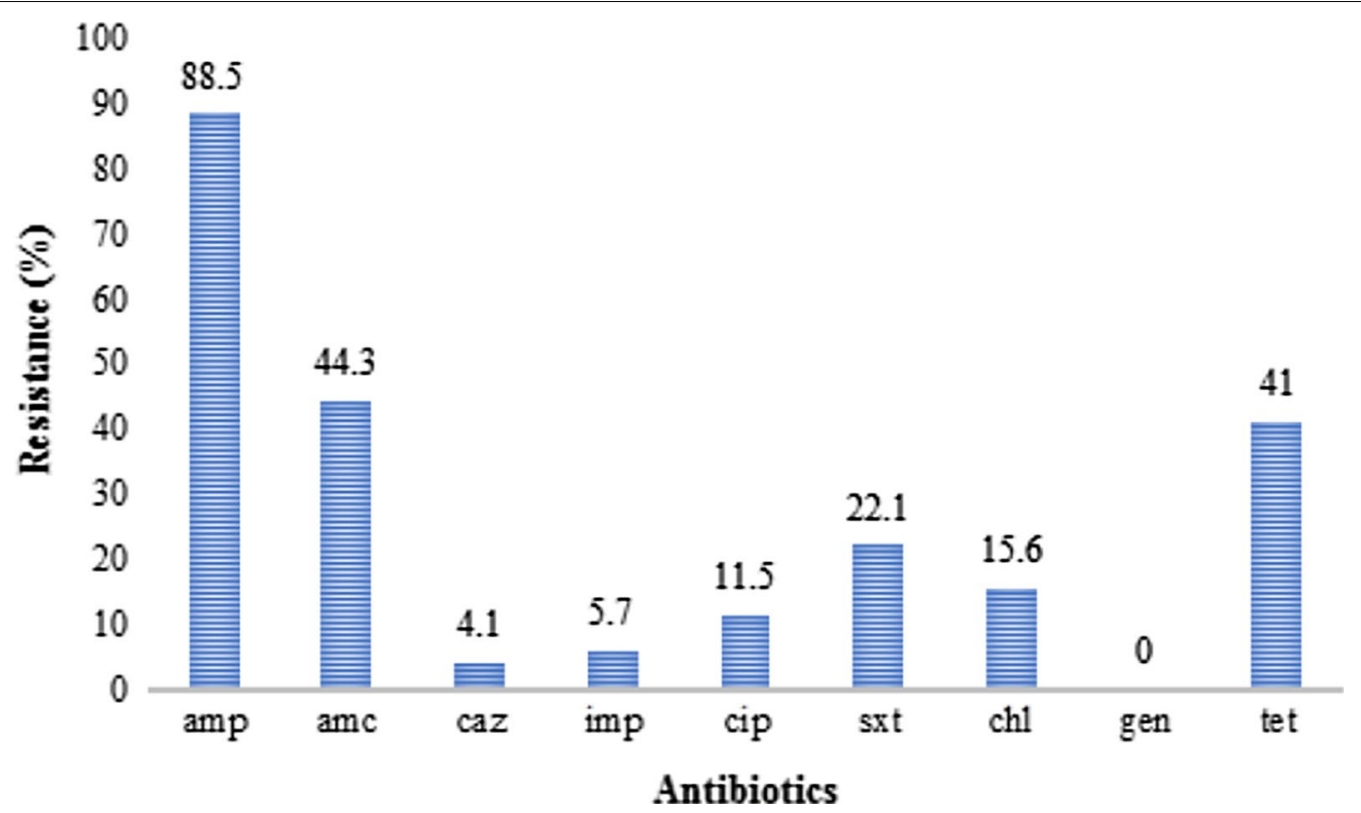

Fig. 2 Resistance of the Vibrio spp. to selected antibiotics. KEY: amp: ampicillin; amc: amoxicillin-clavulanate; caz: ceftazidime; imp: imipenem; cip: ciprofloxacin; sxt: trimethoprim-sulfamethoxazole; chl: chloramphenicol; gen: gentamicin; tet: tetracycline

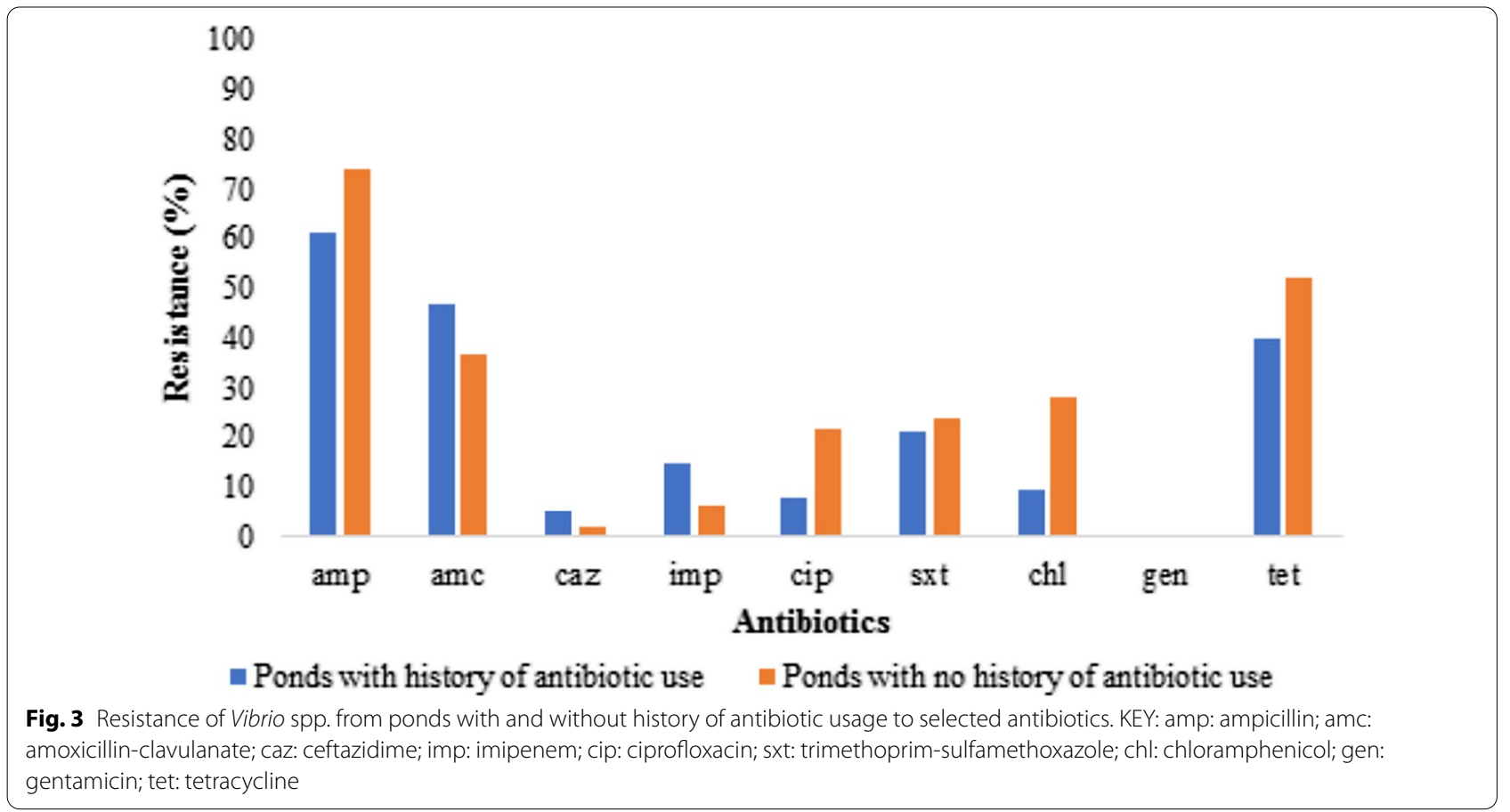

usage as against the ponds without the use of antibiotics with $2.2 \%, 28.3 \%$ and $36.9 \%$ resistance. The resistance to imipenem, ceftazidime, chloramphenicol and amoxicillin-clavulanate was higher in the ponds with history of antibiotic use while resistance to tetracycline, ampicillin, ciprofloxacin and trimethoprim-sulfamethoxazole was higher in ponds without a history of antibiotic usage. 


\section{Discussion}

The use of antibiotics in aquaculture practices for therapeutic purpose and also as growth promoters in some instances has predisposed the microbial flora of the aquaculture environment to antibiotics and hence the need to develop mechanisms to cope with the selective pressure exerted on them by these antimicrobial agents. Metals on the other hand are important components of the natural water systems and are also present in some quantities in aquaculture feeds, and this has led to the evolution of microbes with highly adaptive resistance mechanisms to heavy metals (Kundu et al. 2017; Hui-Gao et al. 2018; Landrigan et al. 2020).

In the present study, a total of one hundred and twentyone Vibrio isolates consisting of Vibrio cholerae (37), Vibrio parahaemolyticus (36), Vibrio vulnificus (36) and Vibrio alginolyticus (12) were obtained from the water samples obtained from the aquaculture ponds. The isolation of Vibrio spp. from aquaculture resources and even some aquatic animals has been reported by several authors. He et al. (2016) reported the isolation of $V$. parahaemolyticus from fresh shrimps in China, while Wei et al. (2014), in their study reported the isolation of $V$. alginolyticus from fish and water samples of a fish hatchery in Asian Seabass. This is in addition to the work of $\mathrm{Hu}$ and Chen (2016), who isolated species of V. parahaemolyticus from crustaceans and shellfish in Shanghai, China. The only major dissimilarity in these studies is the type of fishes and other aquatic animals being reared. In this study, the predominant species of fish being raised is Clarias gariepinus.

The metal composition of the ten selected aquaculture ponds showed the presence of $\mathrm{Cu}, \mathrm{Zn}, \mathrm{Pb}, \mathrm{Ni}$ and $\mathrm{Cr}$ in varying concentration. The $\mathrm{Zn}$ composition of the ponds was between the ranges of $0.19-2.82 \mathrm{mg} / \mathrm{L}$ and this does not corroborate the study of Adeyemi and Ugah (2017) who reported a range of $0.0067-0.0473 \mathrm{mg} / \mathrm{L}$ for $\mathrm{Zn}$ while studying the concentration of some heavy metals in water, soil and fish from some ponds in Abuja, Nigeria. The concentration of $\mathrm{Zn}$ in this study is higher than the recommended national standard of $0.01 \mathrm{mg} / \mathrm{L}$ set by NESREA (2011), implying that the aquaculture ponds are highly contaminated by $\mathrm{Zn}$. The $\mathrm{Cu}$ concentration of the ponds in this study is higher that the range of $0.01-$ $0.10 \mathrm{mg} / \mathrm{L}$ reported by Mustapha and Agunloye (2016) in a study on four different aquaculture ponds. These values are still significantly higher that the recommended national standard of $0.001 \mathrm{mg} / \mathrm{L}$ in some of the ponds in this study.

The $\mathrm{Pb}$ composition of the aquaculture pond water ranged from 0.01 to $0.29 \mathrm{mg} / \mathrm{L}$. With the exception of ponds 1, 2 and 3, whose values were within the accepted quality standards for fisheries and recreation surface water in Nigeria, the $\mathrm{Pb}$ concentration of the water from the remaining seven ponds were well beyond the permissible limits set by NESREA (2011). Ni was not detected in four of the aquaculture ponds, while the range for the remaining six ponds was $0.17-0.47 \mathrm{mg} / \mathrm{L}$, which were well beyond the maximum permissible or acceptable limit in Nigeria as shown in Table 3 . The $\mathrm{Cr}$ concentration for all the selected aquaculture ponds was higher than the minimum permissible limit set by NESREA for $\mathrm{Cr}^{6+}$ suggesting a high level of contamination from the metal (NESREA 2011).

All the Vibrio species isolated in this study survived in the presence of all the metals at a concentration of $6.25 \mu \mathrm{g} / \mathrm{mL}$ to a concentration of $50 \mu \mathrm{g} / \mathrm{mL}$; however, the isolates exposed to $\mathrm{Cu}$ started declining at a concentration of $100 \mu \mathrm{g} / \mathrm{mL}$. There was also a rapid decline in the frequency of isolates as the concentration of $\mathrm{Ni}$ and $\mathrm{Zn}$ reached $200 \mu \mathrm{g} / \mathrm{L}$ and also to $\mathrm{Pb}$ and $\mathrm{Cr}$ at a concentration of $400 \mu \mathrm{g} / \mathrm{mL}$. At a metal concentration of $800 \mu \mathrm{g} /$ $\mathrm{mL}, \mathrm{Zn}$ and $\mathrm{Cu}$ seemed to be toxic to the isolates as they could no longer survive. However, this does not agree with the findings of $\mathrm{Yu}$ et al. (2016) who studied the antibiotic and heavy metal resistance of Vibrio parahaemolyticus isolated from fresh shrimps and reported 93.3\% resistance to copper at a concentration of $3200 \mu \mathrm{g} / \mathrm{mL}$. In addition, no growth was observed at a concentration of $1600 \mu \mathrm{g} / \mathrm{L}$ in the presence of $\mathrm{Pb}$ and $\mathrm{Ni}$. However, $97.5 \%$ of the isolates could grow in the presence of $\mathrm{Pb}$ at a concentration of $400 \mu \mathrm{g} / \mathrm{mL}$ and $91.7 \%$ at a concentration $800 \mathrm{mg} / \mathrm{mL}$; with only 19 isolates (15.7\%) surviving in the presence of $\mathrm{Ni}$ at $800 \mathrm{mg} / \mathrm{mL}$ concentration. This implies that there is no relationship between the level of resistance to metals by the isolates and the concentration of metals in the aquaculture ponds, the only notable exception being $\mathrm{Cr}$, to which the two parameters showed a comparable level of concordance. The level of resistance to metals by the isolates in this study slightly varies when compared with the report of Yu et al. (2016) who isolated $V$. parahaemolyticus from shrimps and reported that $87.8 \%$ were highly resistant to $\mathrm{Pb}$ and only 19 (6.7\%) of their isolates survived in the presence of $\mathrm{Ni}$ at a concentration of $3200 \mu \mathrm{g} / \mathrm{mL}$. There was a high resistance to $\mathrm{Cr}$ in this study, as 117 (96.7\%) of the total Vibrio isolates survived at a concentration of $1600 \mu \mathrm{g} / \mathrm{mL}$ and 57 (47.1\%) survived at the highest concentration of $3200 \mu \mathrm{g} /$ $\mathrm{mL}$. This observation is corroborated by the work of $\mathrm{Yu}$ et al. (2016) who also reported a high resistance to $\mathrm{Cr}$. The high level of resistance to $\mathrm{Cr}$ in this study could be attributed to the elevated concentration of the metal in all the aquaculture ponds studied, which could have facilitated an adaptive mechanism to the metal by the resident bacterial flora of the ponds. 
The Vibrio spp. in this study showed a high level of resistance to ampicillin (88.5\%) in comparison with other antibiotics. The high incidence of resistance to ampicillin aligns with previous studies such as the report of Lim and Kasing (2013) and Heenatigala and Fernando et al. (2016), who reported $100 \%$ resistance to ampicillin in Vibrio isolated from shrimp pond culture. The high level of resistance to ampicillin could be because the antibiotic is one of those being used on the studied aquaculture ponds based on the information obtained from the farm owners, and there might be a high level of adaptation to the antibiotic by the isolates, as a result of prior exposure. This is coupled with the fact that resistance to ampicillin and other $\beta$-lactam antibiotics in Vibrio spp. has been on the increase over the years, as corroborated by the reports of Devi et al. (2009), Ottaviani et al. (2013) and Dahanayake et al. (2019). Of all the isolates obtained in this study, none resisted gentamicin. This observation showed the relative effectiveness of the antibiotic in inhibiting the organisms. This observation is, however, not in concordance with the report of Lim and Kasing (2013) who reported 100\% resistance to gentamicin in their report on antibiotic susceptibility profile of Vibrio parahaemolyticus isolated from Tiger shrimp aquaculture. This could be because gentamicin is rarely used in aquaculture farming and hence low adaptation culminating in a low level of resistance to the antibiotic. This phenomenon was also corroborated by the findings of Apenteng et al. (2017) while studying microbial isolates from some fish ponds in Ghana. The percentage resistance of the Vibrio isolates to amoxicillin-clavulanate and imipenem in this study were $44.3 \%$ and $5.7 \%$, respectively, which is lower than what was reported by Saifedeen et al. (2016) in their study. The resistance to tetracycline in this study was $41 \%$. The obtained resistance is higher than what was reported by Akinbowale et al. (2006) and Amiri et al. (2014), who reported a $5 \%$ and $20.7 \%$ resistance to tetracycline in Vibrio spp. isolated from aquaculture ponds in their respective studies. However, the observed resistance to tetracycline in this study is lower than the $60 \%$ resistance reported by Lim and Kasing (2013) in their study. The resistances of the isolates to trimethoprim-sulfamethoxazole and chloramphenicol in this study were $22.1 \%$ and $15.6 \%$, respectively, which do not correspond with the study of Heenatigala and Fernando (2016) who reported $100 \%$ resistance to chloramphenicol in the Vibrio isolated in their study, same as He et al. (2016). The disparity in the resistance observed in this study and other studies could be due to the volume of antibiotic usage and antibiotic types used in the aquaculture ponds and also the fact that antibiotic usage in the ponds could have placed a selective pressure on the isolates, thus stimulating their resistance to other antibiotics or closely related ones.
There seems to be no correlation between antibiotic resistance in the isolates obtained from the ponds with recognized history of antibiotic usage and the ones without, as there was higher level of resistance to tetracycline, ampicillin, ciprofloxacin, trimethoprim-sulfamethoxazole and chloramphenicol in the isolates obtained from the pond with no recognized history of antibiotic use. With the exception of gentamicin, with no resistance observed in isolates from both categories of ponds, there was higher resistance to imipenem, ceftazidime and amoxicillin-clavulanate in the isolates from ponds with history of antibiotic use. It should be well noted that some studies such as that of Witte (1998), Aarestrup (2012), FAO (2016) and Chen et al. (2021) have suggested a strong association between antibiotics use in agriculture and the onset of antibiotic resistance. In this study, however, the trend might be a little confusing as most aquaculture farm operators do not attest to the use of antibiotics in their farming activities due several underlining factors and the fear of being penalized by certain regulatory authorities.

It should be noted, however, that the presence of heavy metals in aquaculture pond water vis-à-vis the use of antibiotics in the operations of some of the ponds could be a major underlining factor in the development of metal and antibiotic resistance in bacteria from the aquaculture environment. Several studies have reported that the presence of metals could facilitate the phenotypic and genotypic development of resistance to certain antibiotics in a dose-dependent manner (Berg et al. 2010; Knapp et al. 2011, 2017; Bernier and Surette 2013; Dickinson et al. 2019), although the studies of Stepanauskas et al. (2005), Tuckfield and McArthur (2008) and Hölzel et al. (2012) did not agree with that particular assertion. It should be highlighted that $\mathrm{Zn}$ and $\mathrm{Cu}$ have been implicated as major drivers of antibiotic resistance in most bacteria, especially Gram-negative strains (Poole 2017).

\section{Conclusion}

This study has shown the occurrence of heavy metals at concentrations well beyond the maximum permissible limit for fisheries and aquaculture operations in Nigeria. In addition, this study has highlighted the presence of metal- and antibiotic-resistant Vibrio spp. in the aquaculture ponds studied, and this is totally not connected with the prior use of antibiotics in the aquaculture operations. Further studies could be geared toward the detection of other bacterial groups and the molecular characterization of virulent and antibiotic resistance genes in isolated strains. 


\section{Abbreviations}

Zn: Zinc; Cu: Copper; Pb: Lead; Cr: Chromium; Ni: Nickel; CLSI: Clinical and Laboratory Standards Institute; AAS: Atomic absorption spectrophotometer; ARG: Antibiotic resistance gene; FAO: Food and Agriculture Organization.

\section{Acknowledgements}

The authors are grateful to the owners of the aquaculture ponds for granting us access to their fish ponds.

\section{Authors' contributions}

AOA conceived and designed the study. AOA and OGO carried out the laboratory work. AOA and AVO wrote the first draft of the manuscript and did the article formatting. All authors read and approved the final manuscript for publication.

\section{Funding}

The study did not receive any funding.

\section{Availability of data and materials}

The datasets used and/or analyzed during the current study are included in the article.

\section{Declarations}

\section{Ethics approval and consent to participate}

Not applicable.

\section{Consent for publication}

Not applicable.

\section{Competing interests}

The authors declare that there are no competing interests as regards the design and execution of this study.

Received: 12 January 2021 Accepted: 22 June 2021

Published online: 30 June 2021

\section{References}

Aarestrup F (2012) Sustainable farming: get pigs off antibiotics. Nature 486:465-466. https://doi.org/10.1038/486465a

Adeyemi and Ugah (2017) Evaluation of concentration of some heavy metals in water, soil and fish from ponds in Lugbe, Idu and Kuje in the Federal Capital Territory (FCT), Abuja, Nigeria. J Envtl Sci, Toxicol Food Technol 2:39-43. https://doi.org/10.9790/2402-1105033943

Akinbowale O, Peng H, Barton M (2006) Antimicrobial resistance in bacteria isolated from aquaculture sources in Australia. J Appl Microbiol 100:1365-2672. https://doi.org/10.1111/j.1365-2672.2006.02812.x

Amiri A, Amiri S, Behrouzi S, Naseri F, Arabzadeh P, Babaalian A, Khodadadi A (2014) Survey of the sensitivity of Vibrio species isolated from Litopenaeus vannamei to different antibiotics. J Fish Aqua Sci 9(6):1487-495. https://doi. org/10.3923/jfas.2014.487.495

Apenteng JA, Osei-Asare C, Oppong EE, Amihere I, HafizA MY (2017) Antibiotic sensitivity patterns of microbial isolates from fish ponds: a study in the Greater Accra Region of Ghana. Afr J Pharm Pharmacol 11(28):314-320. https://doi.org/10.5897/AJPP2017.4789

Berg J, Thorsen MK, Holm PE, Jensen J, Nybroe O, Brandt KK (2010) Cu exposure under field conditions co-selects for antibiotic resistance as determined by a novel cultivation-independent bacterial community tolerance assay. Envtl Sci Technol 44:8724-8728. https://doi.org/10.1021/ es101798r

Bernier SP, Surette MG (2013) Concentration-dependent activity of antibiotics in natural environments. Front Microbiol 4:20. https://doi.org/10.3389/ fmicb.2013.00020

Centers for Disease Control and Prevention (CDC) (2014) Cholera in Africa.

Clinical and Laboratory Standard Institute (CLSI). 2018. 28th Edition 198-242.

Chen D, Li X, Ni L, Xu D, Xu Y, Ding Y, Xie L, Chen L (2021) First experimental evidence for the presence of potentially toxic Vibrio cholerae in Snails, and Virulence, cross-resistance and genetic diversity of the bacterium in 36 species of aquatic food animals. Antibiotics 10:412

Dahanayake PS, Hossain S, Wickramanayake MVKS, Heo GJ (2019). Prevalence of virulence and extended-spectrum beta-lactamase (ESBL) genes harbouring Vibrio spp. isolated from cockles (Tegillarca granosa) marketed in Korea. Lett. Appl. Microbiol. (in press).

Devi R, Surendran PK, Chakraborty K (2009) Antibiotic resistance and plasmid profiling of Vibrio parahaemolyticus isolated from shrimp farms along the southwest coast of India. World J Microbiol Biotechnol 25:2005-2012. https://doi.org/10.1007/s11274-009-0101-8

Dickinson AW, Power A, Hansen M, Brandt K, Piliposian G, Appleby P, O'Neill $P$, Jones R, Sierocinski P, Koskella B et al (2019) Heavy metal pollution and co-selection for antibiotic resistance: a microbial palaeontology approach. Environ Int 132:105117

Fang J, Shen Y, Qu D, Han J (2019) Antimicrobial resistance profiles and characteristics of integrons in Escherichia coli strains isolated from a largescale centralized swine slaughterhouse and its downstream markets in Zhejiang, China. Food Control 95:215-222

Food and Agriculture Organization. Drivers, dynamics and epidemiology of antimicrobial resistance in animal production. [Internet]. FAO; 2016 [cited 2017 Jan 4]. Available from: http://www.fao.org/3/a-i6209e.pdf. GonzalezCandelas F (2011) The Evolution of Antibiotic Resistance. Gene Evol Infect Dis 305-337. https://doi.org/10.1016/B978-0-12-799942-5.00012-3

Gonzalez-Candelas F (2011) The evolution of antibiotic resistance. Gene Evol Infect Dis 305-337. https://doi.org/10.1016/B978-0-12-799942-5.00012-3

Hatha A, Gomathinayaga R, Lakshmanaperumalsamy P (1993) Incidence of multiple antibiotic resistant Escherichia coli in the Bhavani River. Wrld $J$ Microbiol Biotechnol 9:609-610. https://doi.org/10.1007/BF00386309

He Y, Jin L, Sun F, Hu Q, Chen L (2016) Antibiotic and heavy-metal resistance of Vibrio parahaemolyticus isolated from fresh shrimps in Shanghai fish markets. China Environ Sci Pollut Res 23(15):15033-15040. https://doi. org/10.1007/s11356-016-6614-4

Heenatigala P, Fernando M (2016) Occurrence of bacteria species responsible for vibriosis in shrimp and assessment of the suitable control measures. Sri Lanka J Aqua Sci 21(1):1-17. https://doi.org/10.4038/sljas.v21i1.7481

Hölzel CS, Müller C, Harms KS, Mikolajewski S, Schäfer S, Schwaiger K, Bauer J (2012) Heavy metals in liquid pig manure in light of bacterial antimicrobial resistance. Envtl Res 113:21-27. https://doi.org/10.1016/j.envres.2012. 01.002

Hseu ZY (2004) Evaluating heavy metal contents in nine composts using four digestion methods. Biores Technol 95(1):53-59. https://doi.org/10.1016/j. biortech.2004.02.008

Hu Q, Chen L (2016) Virulence, antibiotic and heavy metal resistance of Vibrio parahaemolyticus isolated from Crustaceans and Shellfish in Shanghai, China. J Food Protect 79:1371-1377. https://doi.org/10.4315/0362-028X. JFP-16-031

Hui-Gao H, Zhang L, Lu Z, He C, Li Q, Na G (2018) Complex migration of antibiotic resistance in natural aquatic environments. Env Pollut 232:1-9. https://doi.org/10.1016/j.envpol.2017.08.078

Kitessa S, Abeywardena M, Wijesundera C, Nichols P (2014) DHA containing oilseed: a timely solution for the sustainability issues surrounding fish oil sources of the health-benefitting long-chain omega-3 oils. Nutrients 6:2035-2058. https://doi.org/10.3390/nu6052035

Knapp CW, Callan AC, Aitken B, Shearn R, Koenders A, Hinwood A (2017) Relationship between antibiotic resistance genes and metals in residential soil samples from Western Australia. Environ Sci Pollut Res 24(3):24842494. https://doi.org/10.1007/s11356-016-7997-y

Knapp CW, McCluskey SM, Singh BK, Campbell CD, Hudson G, Graham DW (2011) Antibiotic resistance gene abundances correlate with metal and geochemical conditions in archived Scottish soils. PLoS ONE 6:e27300. https://doi.org/10.1371/journal.pone.0027300

Kundu GK, Alauddin M, Akter MS, Khan MS, Islam MM, Mondal G, Huque A (2017) Metal contamination of commercial fish feed and quality aspects of farmed tilapia (Oreochromis niloticus) in Bangladesh. Biores Commun 3(1):345-353

Landrigan P, Stegeman J, Fleming L, Allemand D, Anderson D, Backer L Brucker-Davis F, Chevalier N, Corra L, Czerucka D et al (2020) Human Health and Ocean Pollution. Ann Glob Health 86:151

Lee S, Najiah M, Wendy W, Nadirah M, Faizahs H (2009) Occurrence of heavy metals and antibiotics resistance in bacteria from internal organs of American bullfrog (Rana catesbeiana) raised in Malaysia. J Venom Animals 
Tox including Tropic Dis 15:353-358. https://doi.org/10.1590/S167891992009000200016

Lim H, Kasing A (2013) Antimicrobial susceptibilities of Vibrio parahaemolyticus isolates from Tiger Shrimps (Penaeus monodon) Aquaculture in Kuching. Sarawak Res J Microbiol 8(1):55-62. https://doi.org/10.3923/jm.2013.55.62

Magiorakos AP, Srinivasan A, Carey RB, Carmeli Y, Falagas ME, Giske CG, Harbarth S, Hindler JF, Kahlmeter G, Olsson-Liljequist B, Paterson DL (2012) Multidrug-resistant, extensively drug-resistant and pandrug-resistant bacteria: an international expert proposal for interim standard definitions for acquired resistance. Clini Microbiol Infect 18(3):268-281. https://doi. org/10.1111/j.1469-0691.2011.03570.x

Maheshwari M, Nelapati K, Kiranmayi B (2011) Vibrio cholera: a review. Vet World 4:423-438. https://doi.org/10.5455/vetworld.2011.423-428

McIntosh D, Cunningham M, Ji B, Fekete F, Parry E, Clark S, Zalinger Z, Gilg C, Danner G, Johnson A, Beattie M, Ritchie R (2008) Transferable multiple antibiotic and mercury resistance in Atlantic Canadian isolates of Aeromonas salmonicida subsp. salmonicida is associated with carriage of an IncA/C plasmid similar to the Salmonella enterica plasmid. J Antimicrob Chemother 61(6):1221-1228. https://doi.org/10.1093/jac/dkn123

Mustapha M, Agunloye J (2016) Copper toxicity of four different aquaculture ponds. J Trop Sci 6(3):155-159. https://doi.org/10.11594/jtls.06.03.04

Narendrakumar L, Gupta SS, Johnson JB, Ramamurthy T, Thomas S (2019) Molecular adaptations and antibiotic resistance in Vibrio cholerae: a communal challenge. Microb Drug Resist 25:1012-1022

National Environmental Standards and Regulations Enforcement AgencyNESREA, 2011, National Environmental (Surface and Groundwater Quality Control) Regulations, (Abuja, Nigeria: NESREA).

Ottaviani D, Leoni F, Talevi G, Masini L, Santarelli S, Rocchegiani E et al (2013) Extensive investigation of antimicrobial resistance in Vibrio parahaemoIyticus from shellfish and clinical sources. Italy Int J Antimicrob Agents 42:191-193. https://doi.org/10.1016/j.ijantimicag

Poole K (2017) At the nexus of antibiotics and metals: The impact of $\mathrm{Cu}$ and Zn on antibiotic activity and resistance. Trends Microbiol 25(10):820-832. https://doi.org/10.1016/j.tim.2017.04.010
Pradeepkiran JA (2019) Aquaculture role in global food security with nutritional value: a review. Transl Ani Sci 3(2):903-910. https://doi.org/10.1093/ tas/txz012

Sabbir W, Rahman M, Halder T, Nuruzzaman M, Ray S (2018) Assessment of heavy metal contamination in fish feed available in three districts of South Western region of Bangladesh. Intl J Fish Aqua Stud 6(2):100-104 Saifedden G, Farinazleen Nor Khaizura A, Kayali A, Nakaguchi Y, Nishibuchi M, Son R (2016) Antibiotic susceptibility profile of Vibrio parahaemoIyticus isolated from shrimp in Selangor. Malaysia Intl Food Res J 23(6):2732-2736

Stepanauskas R, Glenn TC, Jagoe CH, Tuckfield RC, Lindell AH, McArthur JV (2005) Elevated microbial tolerance to metals and antibiotics in metalcontaminated industrial environments. Env Sci Technol 39:3671-3678. https://doi.org/10.1021/es048468f

Tuckfield RC, McArthur JV (2008) Spatial analysis of antibiotic resistance along metal contaminated streams. Microb Ecol 55:595-607. https://doi.org/10. 1007/s00248-007-9303-5

Wei S, Zhao H, Xian Y, Hussain MA, Wu X (2014) Multiplex PCR assays for the detection of Vibrio alginolyticus, Vibrio parahaemolyticus, Vibrio vulnificus, and Vibrio cholerae with an internal amplification control. Diagn Microbiol Infect Dis 79(2):115-118. https://doi.org/10.1016/j.diagmicrobio.2014.03. 012

Yu H, Lanlan J, Fengjiao S, Qiongxia H, Lanming C (2016) Antibiotics and heavy metal resistance of Vibrio parahaemolyticus isolated from fresh shrimps in Shanghai fish markets, China. Env Sci Pollut Res 23:15033-15040

Witte W (1998) Medical consequences of antibiotic use in agriculture. Science 279:996-997. https://doi.org/10.1007/s11356-016-6614-4

\section{Publisher's Note}

Springer Nature remains neutral with regard to jurisdictional claims in published maps and institutional affiliations.

\section{Submit your manuscript to a SpringerOpen ${ }^{\circ}$ journal and benefit from:}

- Convenient online submission

- Rigorous peer review

- Open access: articles freely available online

- High visibility within the field

- Retaining the copyright to your article

Submit your next manuscript at $\boldsymbol{\nabla}$ springeropen.com 